\title{
Access to information and attitudes towards induced abortion: a community-based study among adults in the City of Colombo, Sri Lanka
}

\author{
Suchira Suranga ${ }^{1 *}$, Kalinga Tudor Silva ${ }^{2}$, Lakshman Senanayake ${ }^{1}$ \\ ${ }^{1}$ Family Planning Association of Sri Lanka; ${ }^{2}$ Faculty of Arts, University of Peradeniya, Sri Lanka \\ *Correspondence: suranga@fpasrilanka.org
}

DOI: http://doi.org/10.4038/jccpsl.v23i1.8086

Received on: 17 August 2016

Accepted on: 27 March 2017

\begin{abstract}
Introduction: Abortion is legally permitted in Sri Lanka, only if it is performed to save the mother's life. However, it is estimated that a large number of induced abortions takes place in Sri Lanka.

Objective: To describe the accessibility of abortion related information and its association with attitudes towards induced abortion in an urban community in Sri Lanka

Methods: A cross-sectional community-based household study was conducted in the City of Colombo among 743 respondents recruited using stratified, cluster sampling method. An interview-administered questionnaire collected data on access to formal and informal sources of information on induced abortion and attitudes on induced abortion and access to information on attitudes. Descriptive statistical analysis and non-parametric hypothesis testing were performed using SPSS software.

Results: The majority of respondents agreed to legalize abortion for rape (65\%), incest (55\%) and pregnancies with lethal foetal abnormalities (53\%). However, less than 7\% agreed to legalize induced abortion for other reasons such as contraceptive failure, bad economic condition and on request. The most common source of information on abortion was informal discussions, followed by the mass media. Access to information on abortion through newspapers, leaflets/handouts, television/ radio programs and news, internet and informal discussions shows a positive association with liberal attitudes towards induced abortion. Access to mass media showed the highest influence in determining abortion attitudes.
\end{abstract}

Conclusion: Access to information was positively associated with the liberal attitudes towards induced abortion.

Key words: access to information, induced abortion, abortion attitudes, communication

\section{Introduction}

Abortion is legally permitted in Sri Lanka only if it is performed to save the mother's life $(1,2)$. Even with a high national contraceptive prevalence rate of $68 \%$ with $50 \%$ using modern methods, some women still face the problem of unwanted pregnancy and resort to abortion in Sri Lanka (3). Along with restrictive laws on abortion and law enforcement mechanisms in the country, women will avoid divulging the fact and therefore, it is difficult to determine the exact prevalence rate for induced abortions. However, a study undertaken in the late 1990s estimated that 125,000 to 175,000 induced abortions, 
mostly illegal are performed annually in Sri Lanka (4). A subsequent study estimated a much higher figure of 658 induced abortions per day, giving an abortion ratio of 741 per 1000 live births (5). The latest study applying Bongaarts' models estimates an induced abortion rate of $0.035,0.147$ and 0.087 per women in years 1993, 2000 and 2007 (6). In the year 2013, the percentage contribution from abortion to maternal mortality was around $10 \%$, making it the third most common cause of maternal death (7).

Previous studies in Sri Lanka have focused on abortion attitudes in sub-segments of the community such as abortion seekers (8), women with a history of abortion (9), women with unwanted pregnancies (9), women with wanted pregnancies (9) legal professions (10) doctors (11) and medical students (11). However, none of these studies focused on the attitudes of the general public towards induced abortion.

As per the research evidence in Sri Lanka, husband/ partner has been involved in the decision making process on abortion most of the time (84\%). In some cases (18\%), the decision had been solely made by the husband/partner. Extended family members have also contributed to the decision among $11 \%$ of the abortion seekers (9).

Individual behaviour and attitudes are highly influenced by the attitudes and norms expressed by others. Neuroscience research suggests that social norms affect neural responses differently depending on the value assigned to stimuli by peers or the society (12). A recent study conducted in Sri Lanka concluded that women's risk of induced abortion was associated with unreliable sources of information during decision making that led to poor knowledge and positive attitudes on its safety (13). After making their decision to abort, the majority of abortion seekers approached their partners and/or immediate associates (friends, neighbors, etc.) to obtain more information about the service providers (persons/ places) available for pregnancy termination and to accompany them to abortionists (13-14). These facts suggest that it is not only the women's attitudes but also the attitudes of the general public would matter when making a decision on abortion. Such general societal attitudes towards induced abortion can also influence the health sector policy response towards providing safe abortion services (15).

The social-psychological theories and past research evidence confirm that information and communication play an important role in changing the pubic attitudes (12, 16-18). Hovland et al (1953) has characterised attitude change as the outcome of persuasive communication (12, 18). As per the information-processing model of persuasion developed by psychologist William McGuire, in order to change listeners' attitudes, one must first capture their attention, and the listeners must comprehend the message. They must then yield to the argument, and retain it until there is an opportunity for action; the final step in attitude change (16). The most persuasive mode of communication takes place when there is personal interaction between the communicator and the recipient $(12,18)$. Cognitive dissonance theory developed by Festinger (1957) argues that changing one's attitude often starts with an initial struggle between old habits or views and new goals or information, which is likely to produce dissonance (12).

Although there are various formal and informal sources of information, different people have different levels of accessibility depending on their personal and socio-demographic characteristics. Access to information contributes towards creating awarenesss on the issue of induced abortion and in turn, shape the attitudes of the general public towards induced abortion.

This study aimed to understand the accessibility of abortion related information in the community and its association with attitudes towards induced abortion. Health authorities may use the results for development of future health policies and programmes.

\section{Methods}

A cross-sectional community-based study was conducted in a representative sample of Households (HHs) in the City of Colombo. The study population consisted of adults aged 19-49 years who had been living in the City of Colombo for at least one year. This setting was selected as it reported the highest rate of abortion (19) and represented all the ethnic groups in Sri Lanka (20) (Table 1). Both males and females were included in the study as previous studies have shown the involvement of all in the decision making process on abortions $(9,13)$.

The sample was recruited from Thimbirigasyaya, one of the two Divisional Secretariat (DS) divisions of Colombo city. It consisted of 20 Grama Niladhari Divisions (GNDs), from which three were selected from each of the following two strata: 10 GNDs reporting 
more than $80 \%$ of households with toilet facilities and the other 10 GNDs reporting otherwise (20), using cluster sampling with probability proportionate to the size. The selected GNDs were divided into housing clusters based on the housing data derived from the 2012 department of election report. Five to eight housing clusters and $50 \mathrm{HHs}$ were selected from each GND using a systematic $\mathrm{HH}$ selection method. The sample size was calculated as $300 \mathrm{HHs}$ based on the sample size calculation formula for HH surveys (21) with $95 \%$ confidence interval, $10 \%$ precision (margin of error $=$ 0.06 ) and 0.64 expected proportion of residents between the age 19-49 from the total population (20). Every eligible person in all the selected households willing to participate in the study was interviewed.

Respondents were administered a questionnaire that assessed the socio-demographic characteristics including $\mathrm{HH}$ socio-economic status and access to different sources of information (formal and informal) on induced abortion. Respondents were asked to recall their memories on access to abortion related information through newspapers, television/radio news or programs during the past 12 months, and through formal education, leaflets/handouts, internet, health professionals and informal discussions during their lifetime.

Attitudes on abortion were assessed using a standard data collection tool which had been adapted to Sri Lankan context. The original tool had been validated and used in other countries (22-26), and shows acceptable internal validity with 0.883 Cronbach's alpha. Attitudes were assessed based on the level of agreement on 10 specific circumstances. Each question was scored on a Likert scale (1-Strongly disagree to 5-Strongly agree), which was summed up to measure the overall attitudes towards abortion. This aggregated score ranged from 10 to 50, where lower scores reflected conservative attitudes and higher scores the liberal attitudes.

Data were obtained by a team of well-trained enumerators who were recruited from the Sociology Special graduates of University of Colombo. They were trained on administering the questionnaire, ethical considerations as well as maintaining privacy and confidentiality. Interviews were conducted in a confidential environment (one on one) without the involvement of and within the hearing of a third person.

\section{Data Analysis}

Data were statistically analysed using SPSS software. Further to the descriptive analysis with frequencies and percentages, non-parametric hypothesis testing for differences such as Mann Whitney U test, Kruskal-Wallis test and median test were performed.

\section{Results}

Successful responses were provided from $271 \mathrm{HHs}$ while the remaining $29 \mathrm{HHs}$ had no person eligible or willing to participate in the study. Of the 825 persons available in the consenting HHs, 743 provided responses $(90.06 \%)$. The average age of respondents was 33 years $(\mathrm{SD}=11.15)$. The majority consisted of females (58.78\%). Table 1 describes the socio-demographic characteristics of the sample.

\section{Access to information on abortion}

Access to information on abortion varied from formal sources such as school and higher education, printed and mass media and formal interactions with service providers, to informal sources such as discussions with friends, relations and family members (Table 2).

Of the two channels of communication, informal discussions were shown to be the most popular source related to abortion. Only 31\% of the respondents had received services from the public health staff at some point in their adulthood. However, $61 \%$ of those who received such services had received some information related to abortion, with $91 \%$ of them receiving it during the ante-natal visits. There was no significant association $(p<0.001)$ between access to information through public health services and respondents' ethnicity, suggesting all having an equal chance of receiving abortion related information from the state health system.

Among the males, the common sources of information on abortion were television/radio, informal discussion and school education. Relatively lower access through health service staff is noteworthy. Among the females, it was mainly through informal discussions and public health staff, and less through television and radio. Access of information during school education was more or less similar between males and females. Only $29 \%$ had access to any leaflet or publication on abortion produced by the Ministry of Health (n=9), Family Planning Association ( $\mathrm{n}=2$ ), Family Health Bureau (n=1), Faculty of Medicine ( $\mathrm{n}=1)$, and World Health Organization ( $\mathrm{n}=1)$. Only one out of two respondents who have undergone higher education had access to information related to abortion. 
Table 1. Socio-demographic profile of the respondents including a comparison with national, district and divisional secretariat divisional censes

\begin{tabular}{|c|c|c|c|c|}
\hline \multicolumn{2}{|l|}{ Category } & \multicolumn{2}{|r|}{ Sample } & $\begin{array}{c}\text { Colombo District } \\
\%\end{array}$ \\
\hline \multirow[t]{2}{*}{ Sex } & Female & 435 & $58.78 \%$ & $50.78 \%$ \\
\hline & Male & 305 & $41.22 \%$ & $49.21 \%$ \\
\hline \multirow[t]{2}{*}{ Age } & $19-24$ & 255 & $34.32 \%$ & \\
\hline & $25-49$ & 488 & $66.68 \%$ & \\
\hline \multirow[t]{5}{*}{ Ethnicity } & Sinhalese & 384 & $51.68 \%$ & $76.69 \%$ \\
\hline & Muslim & 131 & $17.63 \%$ & $11.05 \%$ \\
\hline & Indian Tamil & 16 & $2.15 \%$ & $1.18 \%$ \\
\hline & Sri Lankan Tamil & 205 & $27.59 \%$ & $10.01 \%$ \\
\hline & Burger & 7 & $0.94 \%$ & $0.58 \%$ \\
\hline \multirow[t]{5}{*}{ Religion } & Buddhist & 316 & $42.53 \%$ & $70.66 \%$ \\
\hline & Islam & 136 & $18.30 \%$ & $11.76 \%$ \\
\hline & Hindu & 165 & $22.21 \%$ & $7.89 \%$ \\
\hline & Roman Catholic & 50 & $6.73 \%$ & $6.80 \%$ \\
\hline & Christian & 76 & $10.23 \%$ & $2.75 \%$ \\
\hline Level of & Less than Year 5 & 9 & $1.23 \%$ & \\
\hline \multirow[t]{5}{*}{ Education } & Year 5-7 & 54 & $7.36 \%$ & \\
\hline & Year 8-10 & 146 & $19.89 \%$ & \\
\hline & GCE O/Level and A/Level & 442 & $60.22 \%$ & \\
\hline & Higher education or Degree & 57 & $7.77 \%$ & \\
\hline & Post graduate & 26 & $3.54 \%$ & \\
\hline \multirow[t]{4}{*}{ Marital Status } & Married & 396 & $53.44 \%$ & \\
\hline & Never Married & 317 & $42.78 \%$ & \\
\hline & Divorced & 7 & $0.94 \%$ & \\
\hline & Widow & 21 & $2.83 \%$ & \\
\hline
\end{tabular}

${ }^{1}$ Source:- Department of Census and Statistics, 2012 
Table 2. The number and percentage of respondents with access to abortion information

\begin{tabular}{|c|c|c|c|c|c|c|}
\hline & \multicolumn{6}{|c|}{$\begin{array}{l}\text { No. and \% of respondents } \\
\text { who accessed abortion related information }\end{array}$} \\
\hline & \multicolumn{2}{|c|}{$\begin{array}{l}\text { Female } \\
(n=435)\end{array}$} & \multicolumn{2}{|c|}{$\begin{array}{c}\text { Male } \\
(n=305)\end{array}$} & \multicolumn{2}{|c|}{$\begin{array}{c}\text { Total } \\
(n=740)\end{array}$} \\
\hline & No. & $\%$ & No. & $\%$ & No. & $\%$ \\
\hline \multicolumn{7}{|l|}{ Formal Education } \\
\hline School education & 53 & $12.18 \%$ & 49 & $16.07 \%$ & 102 & $13.78 \%$ \\
\hline Higher education & 37 & $8.51 \%$ & 12 & $3.93 \%$ & 49 & $6.62 \%$ \\
\hline \multicolumn{7}{|l|}{ Printed and Mass Media } \\
\hline Newspapers & 30 & $6.90 \%$ & 46 & $15.08 \%$ & 76 & $10.27 \%$ \\
\hline TV or Radio news & 74 & $17.01 \%$ & 161 & $52.79 \%$ & 235 & $31.76 \%$ \\
\hline Movie, Film or Tele drama & 15 & $3.45 \%$ & 10 & $3.28 \%$ & 25 & $3.38 \%$ \\
\hline \multicolumn{7}{|l|}{ Internet } \\
\hline Internet (web site or web page) & 14 & $3.22 \%$ & 12 & $3.93 \%$ & 26 & $3.51 \%$ \\
\hline \multicolumn{7}{|l|}{ Health Services } \\
\hline Public health staff & 131 & $30.11 \%$ & 12 & $3.93 \%$ & 143 & $19.32 \%$ \\
\hline Private practitioner / Family Doctor & 60 & $13.79 \%$ & 13 & $4.26 \%$ & 73 & $9.86 \%$ \\
\hline Leaflet, handouts, educational material & 15 & $3.45 \%$ & 14 & $4.59 \%$ & 29 & $3.92 \%$ \\
\hline \multicolumn{7}{|l|}{ Informal Communication } \\
\hline Informal discussions with any below & 185 & $42.53 \%$ & 85 & $27.87 \%$ & 270 & $36.49 \%$ \\
\hline Parents & 31 & $7.13 \%$ & 1 & $0.33 \%$ & 32 & $4.32 \%$ \\
\hline Other family members & 17 & $3.91 \%$ & 9 & $2.95 \%$ & 26 & $3.51 \%$ \\
\hline Neighbour & 31 & $7.13 \%$ & 3 & $0.98 \%$ & 34 & $4.59 \%$ \\
\hline Close friend / Peer & 156 & $35.86 \%$ & 25 & $8.2 \%$ & 181 & $24.46 \%$ \\
\hline Teacher & 22 & $5.06 \%$ & 0 & $0.0 \%$ & 22 & $2.97 \%$ \\
\hline Husband/wife & 22 & $5.06 \%$ & 36 & $11.8 \%$ & 58 & $7.84 \%$ \\
\hline Intimate partner & 2 & $0.46 \%$ & 7 & $2.3 \%$ & 9 & $1.22 \%$ \\
\hline Health care provider & 22 & $5.06 \%$ & 16 & $5.25 \%$ & 38 & $5.14 \%$ \\
\hline Other & 2 & $0.46 \%$ & 0 & $0.0 \%$ & 2 & $0.27 \%$ \\
\hline
\end{tabular}

* Significant at 95\% Confidence Interval 


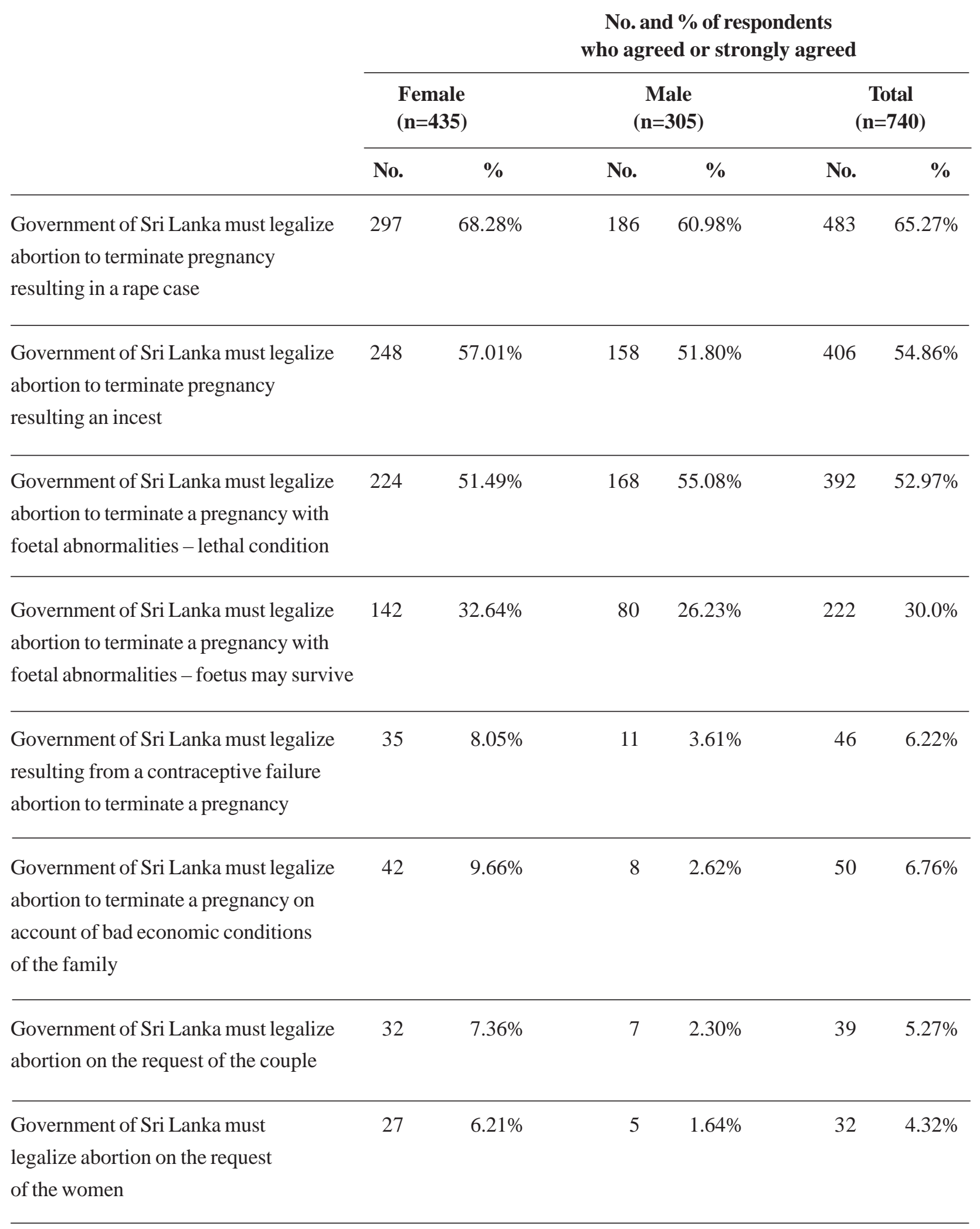


Table 4. Access to information as a factor associated with attitudes towards abortion

\begin{tabular}{|c|c|c|c|c|c|c|c|c|c|}
\hline \multirow[t]{2}{*}{ Variables and Levels } & \multicolumn{3}{|c|}{ Frequency } & \multicolumn{4}{|c|}{ Abortion Attitudes Score } & \multirow[b]{2}{*}{$\begin{array}{l}\text { Test for } \\
\text { median }\end{array}$} & \multirow{2}{*}{$\begin{array}{r}\text { Mann } \\
\text { Whitney U } \\
\text { test / } \\
\text { Kruskal } \\
\text { Wallis test }\end{array}$} \\
\hline & Levels & $\mathbf{N}$ & $\%$ & Mean & Median & $\begin{array}{l}\text { Mean } \\
\text { Rank }\end{array}$ & SD & & \\
\hline \multirow{3}{*}{$\begin{array}{l}\text { Have you come across and read } \\
\text { any newspaper article on abortion } \\
\text { during the past year? }\end{array}$} & No & 93 & $55 \%$ & 26.49 & 28.0 & 77 & 7.10 & $\mathrm{p}=0.147$ & $\mathbf{p}=0.033^{*}$ \\
\hline & Yes & 77 & $45 \%$ & 28.62 & 29.0 & 93 & 8.59 & & $X^{2}=4.529$ \\
\hline & Total & 170 & $100 \%$ & 27.45 & 28.0 & N/A & 7.86 & & $\begin{array}{r}\text { Effect } \\
\text { size }=3 \%\end{array}$ \\
\hline 2) Have you ever read any kind of & No & 512 & $95 \%$ & 26.06 & 27.8 & 258 & 9.07 & $\mathrm{p}=0.001 * *$ & $\mathbf{p}=\mathbf{0 . 0 0 0}{ }^{* *}$ \\
\hline leaflet, handout or article related & Yes & 29 & $5 \%$ & 32.08 & 33.0 & 373 & 6.05 & & $X^{2}=15.822$ \\
\hline $\begin{array}{l}\text { to abortion published by } \\
\text { any institute? }\end{array}$ & Total & 541 & $100 \%$ & 26.38 & 28.0 & N/A & 9.03 & & $\begin{array}{r}\text { Effect } \\
\text { size }=3 \%\end{array}$ \\
\hline 3) Have you heard any TV/Radio & No & 145 & $38 \%$ & 25.02 & 26.0 & 166 & 7.59 & $\mathrm{p}=\mathbf{0 . 0 3 8} *$ & $\mathrm{p}=0.001^{* *}$ \\
\hline news on abortion during the & Yes & 236 & $62 \%$ & 27.76 & 28.0 & 203 & 7.05 & & $X^{2}=10.282$ \\
\hline past year? & Total & 381 & $100 \%$ & 26.71 & 28.0 & N/A & 7.37 & & $\begin{array}{r}\text { Effect } \\
\text { size }=3 \%\end{array}$ \\
\hline 4) Have you ever watched any kind & No & 573 & $96 \%$ & 26.27 & 28.0 & 287 & 8.83 & $\mathrm{p}=0.01^{*}$ & $\mathbf{p}=0.00^{* *}$ \\
\hline of TV programme, movie, film or & Yes & 25 & $4 \%$ & 33.02 & 33.0 & 427 & 6.54 & & $X^{2}=16.46$ \\
\hline drama related to abortion? & Total & 598 & $100 \%$ & 26.56 & 28.0 & N/A & 8.84 & & $\begin{array}{r}\text { Effect } \\
\text { size }=3 \%\end{array}$ \\
\hline 5) Have you ever come across and & No & 322 & $93 \%$ & 27.76 & 28.0 & 169 & 8.02 & $\mathrm{p}=0.074$ & $\mathrm{p}=\mathbf{0 . 0 1 8 ^ { * }}$ \\
\hline read a website or web page & Yes & 26 & $7 \%$ & 31.55 & 30.0 & 217 & 6.5 & & $X^{2}=5.607$ \\
\hline related to abortion? & Total & 348 & $100 \%$ & 28.04 & 28.0 & N/A & 7.97 & & $\begin{array}{r}\text { Effect } \\
\text { size }=2 \%\end{array}$ \\
\hline 6) Have you ever been sensitized & No & 88 & $38 \%$ & 26.21 & 26.0 & 110 & 9.33 & $\mathrm{p}=0.849$ & $\mathrm{p}=\mathbf{0 . 3 8 9}$ \\
\hline on abortion by your public & Yes & 143 & $62 \%$ & 26.84 & 28.0 & 118 & 8.02 & & $X^{2}=0.743$ \\
\hline health staff? & Total & 231 & $100 \%$ & 26.60 & 28.0 & N/A & 8.53 & & $\begin{array}{r}\text { Effect } \\
\text { size }=0 \%\end{array}$ \\
\hline 7) Have you ever been given & No & 666 & $90 \%$ & 26.84 & 28.0 & 363 & 8.52 & $\mathrm{p}=0.533$ & $\mathrm{p}=0.933$ \\
\hline information on abortion by a & Yes & 73 & $10 \%$ & 27.11 & 28.0 & 361 & 7.68 & & $\mathrm{X}^{2}=0.007$ \\
\hline $\begin{array}{l}\text { private practitioner or by your } \\
\text { family doctor? }\end{array}$ & Total & 739 & $100 \%$ & 26.87 & 28.0 & N/A & 8.44 & & $\begin{array}{r}\text { Effect } \\
\text { size }=0 \%\end{array}$ \\
\hline 8) Have you ever discussed & No & 467 & $63 \%$ & 26.01 & 27.0 & 338 & 8.39 & $\mathrm{p}=0.052$ & $\mathbf{p}=0.000^{* *}$ \\
\hline induced abortion with any other & Yes & 271 & $37 \%$ & 28.42 & 28.0 & 405 & 8.26 & & $X^{2}=17.248$ \\
\hline $\begin{array}{l}\text { person like parents, family } \\
\text { members, friends, etc.? }\end{array}$ & Total & 738 & $100 \%$ & 26.89 & 28.0 & N/A & 8.42 & & $\begin{array}{r}\text { Effect } \\
\text { size }=2 \%\end{array}$ \\
\hline
\end{tabular}

* Statistically significant at 95\% confidence interval

** Statistically significant at 99\% confidence interval 
There was no significant association $(\mathrm{p}<0.05)$ between access to abortion related information through television, radio or newspapers and the respondents' ability to listen and understand any particular language (Sinhala, Tamil or English). However, there was a significant association $(\mathrm{p}<0.05)$ between access to abortion information through movies or tele-drama and the ability to listen and understand English language. Respondents who could read and understand English language $(\mathrm{p}<0.001)$ or Sinhala language $(\mathrm{p}=0.046)$ were also more likely to receive abortion related information through leaflets or similar publications.

Relatively, a significantly lower proportion of Muslims (24.62\%) have received abortion related information from informal sources compared to other ethnic groups (Sinhalese $=40.68 \%$, Sri Lankan Tamil $=37.56 \%$, Other $=31.82 \%)(\mathrm{p}=0.011)$.

\section{Attitudes towards induced abortion}

As described in Table 3, majority of the respondents agreed that there is a need to legalize abortion for certain conditions such as rape (65\%), incest (55\%) and lethal foetal abnormalities (53\%). However, of the total sample, only $30 \%$ agreed with the need to legalize abortion when the abnormality was non-lethal. Less than $7 \%$ of the respondents agreed to legalize abortion for all other circumstances.

\section{Association between access to information and attitudes towards abortion}

As shown in Table 4, access to most of the information sources showed significant positive associations with respondents' liberal attitudes towards abortion. None of the information sources showed any negative associations. In other words, the respondents with higher accessibility to sources of information were likely to have more liberal attitudes towards the abortion laws in Sri Lanka. However, it was not so with interventions of the public or the private health systems.

\section{Discussion}

The above findings clearly show that school education has a very limited contribution towards providing abortion-related information to the general community. Although higher education is more effective, only a small segment of the community has the opportunity to access higher education. The implementation of a formal national level comprehensive sexuality education programme for in school and out of school youth is important. It is important to identify deficiencies in school curriculum that prevent students from learning reproductive health issues such as induced abortion. The skills of school teachers in teaching reproductive health related issues to students should be reassessed and deficiencies must be corrected. The education and health ministries with the assistance of non-governmental organizations should plan integrated strategies to meet this need among school students.

Mass media and other formal communication campaigns have the greatest effect on changing public attitudes on induced abortion. However, the number of respondents who have accessed abortion related information through mass media was very low. Provision of reliable and quality assured messages through mass media seems a priority to address the issue. Providing correct information related to abortion and by developing and adopting a comprehensive mass media strategy seems to be an immediate requirement in this sector.

Informal communication with peers was identified as the most common source of information on induced abortion. Although most of the females seek abortion related information from their friends or peers, the reliability of that information is questionable. A previous study conducted among women who had undergone induced abortion shows that a large proportion (69\%) was able to find information on abortion service provider through a friend or relative (9). Arambepola and Rajapaksa concluded in their study that the women's risk of induced abortion is associated with unreliable sources of information during decision making that led to poor knowledge and positive attitudes on its safety. When making a decision, the risk of undergoing an induced abortion was significant among those who sought assistance with more reliance placed on non-medical sources such as spouse/partner, friend, neighbour and family/relation (13). These facts indicate that females rely on the information received from their friends or peers even after undergoing unintended pregnancies making them more vulnerable to induced abortion. A peer education programme conducted in Ampara and Batticaloa districts to address the issue related to teenage pregnancy has been successful. Therefore, well focused peer education interventions through behavioural change communication approaches for out of school girls in the areas reporting high prevalence of reproductive health issues such as induced abortion could be successful. 
Although the number of people accessing information on abortion by reading leaflets and other publications is small, its effect on liberalizing public attitudes is not negligible. However, it is important to note that the respondents who can read only in Tamil language have had a relatively lower chance in accessing abortion related information through leaflets or any other publication $(\mathrm{p}<0.001)$. This highlights that information, education and communication material must be published in all the local languages, even in a city like Colombo where the majority can read Sinhala language.

Results show that Muslim respondents are less likely to receive abortion related information through information sources such as peers, spouse, etc. in comparison to other ethnic groups. Inter-spouse communication on contraception and family planning is also lower among Sri Lankan Muslim couples compared to other ethnic groups $(27,28)$. Thalagala (2010) too highlighted the Muslim respondents showing the strongest sensitivity on induced abortion than Tamils and Sinhalese (9). Lack of interpersonal communication may have contributed to the prevailing conservative attitudes of the Muslim community towards induced abortion in comparison to other ethnic groups (29). Therefore, the Muslim community must be one of the priority social segments in future interventions.

Results show that the residents in Colombo city are not ready to liberalize the abortion law probably for soft reasons (e.g. contraceptive failure, economic reasons, on request, etc.). Therefore, legalizing abortion for these reasons may develop social unrest. However, in view of the public acceptance, government may consider legalizing induced abortion for rape, incest and foetus with lethal abnormalities. However, liberalizing the law on abortion to include cases of rape, incest and foetal abnormality would not significantly reduce the current rate of illegal abortions. This is because the previous studies have shown that the number of induced abortions following rape, incest and foetal abnormality are less than $5 \%(11,30)$. Experiences in other countries confirm that liberal laws alone will not solve the issue of induced abortion. As such, all other related factors must be considered when formulating national policies and legislatives on abortions.

\section{Limitations of the Study}

This sample drawn from Colombo city is very different from other areas in relation to ethnic, religious socio-economic characteristics. Only those aged 19-49 were sampled, thus findings cannot be generalized to other age groups. Response rate of the study was only $72.2 \%$ due to practical difficulties in data collection in this highly urbanized setting.

\section{Conclusion and Recommendations}

Urban residents in Colombo City demonstrated conservative attitudes towards legalization of abortion. However, a majority supported legalization of abortion under rape, incest and lethal foetal abnormality conditions. Among the males, the common sources of information on abortion were television/radio, informal discussion and school education. In contrast, females relied on the information received through informal discussions and public health staff. Relatively lower access through health service staff is noteworthy. Access to information was positively associated with liberal attitudes towards induced abortion.

\section{Public health implications}

Findings of this study will provide inputs in formulation of national policies and strategies for prevention of unsafe abortions in Sri Lanka. Specially, the results will guide in designing of communication strategies and public health programmes for changing attitudes and behaviour of the general public for prevention of unsafe abortion.

\section{Author Declarations}

Competing interests: No financial or non-financial conflict of interest .

Ethics approval and consent to participate: Ethical Approval was received from the Ethical Review Committee of the Sri Lanka Medical Association.

Funding: None.

Acknowledgements: We thank the team of enumerators headed by Ms. Chamari Kumari De Thabrew, Prof. Indralal De Silva, Prof. Wanigasundara, Prof. S. Samitha, Prof. WMK Wijethunga, Dr. Sumithra Tissera, Ms. Natasha de Rosayro, Mr. Duminda Rajakaruna, Mr. Kalhara 
Senadhira, Dr. Thiloma Moonasinghe, Dr. Heshan Wickramasinghe, Mr. Mahinda Deshapriya, Mr. RVP Rajapakshe, Mr. Thilina Wickramarathne, Mr. Chaminda Hettiarachchi, Ms. Mallika Samarawickrama and Mr. Krishan Yogeshwaran.

Author contributions: MSS was the principal investigator of the study. KTS and LS were contributed to the conceptualization and study design. MSS was involved in sample design, data collection, statistical analysis and drafting the manuscript. KTS and LS reviewed the paper critically for important intellectual content and finalized the paper.

\section{References}

1. Sri Lanka Penal Code Section 303. Available from: http:// www1.umn.edu/humanrts/research/srilanka/statutes/ Penal_Code.pdf.

2. Senanayake L, Willatgamuwa S, Moonasinghe L, Tissera S. Unwanted / unplanned pregnancies and their aftermath. Colombo: The Family Planning Association of Sri Lanka in collaboration with the College of General Practitioners of Sri Lanka, 2012.

3. Senanayake L. Prevention of unsafe abortion in Asia Oceania Region. Asia Oceania Federation of Obstetrics and Gynecology, 2009.

4. De Silva IW. The practice of induced abortion in Sri Lanka. Harvard School of Public Health: Takemi Program in International Health 137, 1997.

5. Rajapaksa LC. Estimates of induced abortion using RRT Technique. Colombo, 2000.

6. Abeykoon ATPL. Estimates of abortion rate in Sri Lanka using Bongaarts model of proximate determinants of fertility. Colombo: The United Nations Population Fund, 2012.

7. Family Health Bureau. Annual Report on Family Health 2013. Colombo: Family Health Bureau, 2014.

8. Rajapaksa LC, De Silva IW. Profile of women seeking abortion. Colombo: University of Colombo, 2000.

9. Thalagala N. Unsafe abortions in Sri Lanka - facts and risk profile. Journal of the College of Community Physicians of Sri Lanka 2012; 15(1).

10. Dalvie S, Batua A, De Silva WI. A study of knowledge, attitudes and understanding of legal professionals about safe abortion as a woman's right. Available from: http:// asap-asia.org/wp-content/uploads/2015/01/Philippines_ Abortion_Booklet_Update.pdf.
11. Senanayake L, Willatgamuwa S, Jayasinghe K. Reducing the burden of unsafe abortion in Sri Lanka - A situation analysis and plan of action. Colombo: Family Planning Association of Sri Lanka, 2008.

12. Petty RE, Brinol P. Attitude change. Advanced social psychology: the state of the science 2010: 217-259.

13. Arambepola C, Rajapaksa LC. Decision making on unsafe abortions in Sri Lanka: a case-control study. Reproductive Health 2014; 11(1); 91.

14. Arambepola C, Rajapaksa LC. Hospital based study on unintended pregnancies in Sri Lanka. Colombo: United Nations Population Fund, 2014.

15. Jelen TG, Wilcox C. Causes and consequences of public attitudes toward abortion: a review and research agenda. Political Research Quarterly 2003; 56(4): 489-500.

16. Johnson BT, Maio GR, Smith-McLallen A. Communication and attitude change: causes, processes, and effects. The handbook of attitudes 2005; 617-669.

17. Happer C, Philo G. The role of the media in the construction of public belief and social change. Journal of Social and Political Psychology 2013; 1(1): 321-36.

18. Cascio CN, Dal Cin S, Falk EB. Health communications: Predicting behavior change from the brain. Social Neuroscience and Public Health. P A Hall. New York: Springer, 2013.

19. De Silva, WI. The Practice of Induced Abortion in Sri Lanka. Boston: Harvard School of Public Health, 1997.

20. Census of Population and Housing 2011. Colombo: Department of Census and Statistics, 2012.

21. United Nations Secretariat. Designing Household Survey Samples: practical guidelines. Department of Economic and Social Affairs, Statistics Division, 2006. Available from: http://unstats.un.org/unsd/demographic/sources/surveys/ Handbook23June05.pdf.

22. Cook EA, Jelen TG, Wilcox C. Measuring public attitudes on abortion: methodological and substantive considerations. Family Planning Perspectives 1993: 118-45.

23. Harris RJ, Mills EW. Religion, values and attitudes toward abortion. Journal for the Scientific Study of Religion 1985: 137-154.

24. Emerson MO. Through tinted glasses: Religion, worldviews, and abortion attitudes. Journal for the Scientific Study of Religion 1996: 41-55.

25. Wilcox C. Race, religion, region and abortion attitudes. Sociology of Religion 1992; 53(1): 97-105. 
26. Walzer S. The role of gender in determining abortion attitudes. Social Science Quarterly 1994.

27. De Silva WI. Husband-wife communication and contraceptive behaviour in Sri Lanka. Journal of Family Welfare 1994; 40(2): 1-3.

28. De Silva WI, Rajapaksa LC. Desired fertility and family planning: husband and wife communication in Sri Lanka. Asian Profile 1997; 25:397-412.
29. Suranga MS, Silva, KT, Senanayake L. Attitudes of adults concerning induced abortion and abortion law - a community based study in Colombo City of Sri Lanka. 8th Asia Pacific Conference on Reproductive and Sexual Health and Rights, Nay Phi Taw, Myanmar, 2016.

30. Perera J, De Silva IW, Gange H. Knowledge behavior and attitude on induced abortion and family planning among Sri Lankan women seeking termination of pregnancy. Ceylon Medical Journal 2004; 49: 7-14. 